\title{
Motivações para a prática e não prática desportiva
}

\section{Motivations for practice and non-practice of sports}

\author{
E. Martins, D. Borges, M. Ferreira, M. Mano
}

ARTIGO ORIGINAL | ORIGINAL TITLE

\begin{abstract}
RESUMO
Este estudo tem por objectivo conhecer as motivações que levam os indivíduos à prática e não prática desportiva. A amostra foi constituída por 186 indivíduos sendo 100 do sexo feminino e 86 do sexo masculino com idades compreendidas entre os 18 e os 35 anos de idade. Foram aplicados como instrumentos: o Questionário de Motivação para as Actividades Desportivas - QMAD e o Inquérito de Motivações para a Ausência de Actividade Desportiva - IMAAD. Os resultados indicaram que existem diferenças entre sexos no que se refere aos motivos para a prática e não prática desportiva. Os motivos mais importantes para a prática foram "estar em boa condição física", "fazer exercício" e "manter a forma" e os menos importantes foram "ser conhecido", "ter a sensação de ser importante" e " pretexto para sair de casa". Os motivos mais importantes para a não prática foram "falta de hábitos desportivos", "por preguiça" e "falta de interesse, de vontade".

Palavras-chave: motivação, prática desportiva, jovens, adolescentes
\end{abstract}

\begin{abstract}
This study aims to know the motivations that lead individuals to practice and not practice sports. The sample consisted of 186 individuals, of whom 100 were female and 86 males aged between 18 and 35 years. The following were applied as instruments: the Motivation Questionnaire for Sports Activities - QMAD and the Motivation Survey for the Absence of Sports Activity - IMAAD. The results indicated differences between sexes regarding the reasons for the practice and not practice sports. The most important reasons referred for sports practice were "being in good physical condition", "exercising," and "keeping fit," and the least important were "being known," "having the feeling of being important," and "pretext to leave House." The most important reasons for non-practice were "lack of sports habits", "laziness," and "lack of interest, will."
\end{abstract}

Keywords: motivation, sport practice, youngsters, adolescents

Submetido: 03.12.2018 | Aceite: 06.18.2019

Edith Martins, Diana Borges, Marco Ferreira, Miriam Mano. Psicólogas em Consulta e Formação Privada.

Endereço para correspondência: Miriam Mano. Psicólogo Clínica. na Mirian Psicologia. 10, Place de la Paix, L- 4275 Esch-SurAlzettr, Luxemburg.

E-mail: miriam.mano@gmail.com 
A motivação tem sido alvo de muitas investigações e discussões em diferentes contextos, sendo considerada por muitos autores (Araújo, et al., 2007) a chave de qualquer acção humana e reconhecida nas várias áreas da actividade física, mostrando-se benéfica tanto ao nível biológico, como ao nível psicológico.

Quando se fala em motivação convém lembrar que, o motivo é a base do processo motivacional, tratando-se portanto, do elemento essencial para o despoletar da iniciativa e posterior manutenção da actividade realizada pelo Homem (Moreno, Dezan, Duarte, \& Schwartz, 2006). Nesta perspectiva, o motivo é um factor interno, que dá início, dirige e integra o comportamento de uma pessoa. A motivação tem a sua origem na palavra motivo, como uma força intrínseca, um impulso, um propósito, levando o indivíduo a actuar de determinada forma dirigindo as suas acções e a intensidade dos esforços para atingir um objectivo.

Alguns motivos têm maior influência sobre outros determinando a escolha de um tipo de acção/comportamento por parte do indivíduo. Moreno et. al. (2006) afirmam também que cada motivo apresenta uma força distinta, no entanto, o facto de um indivíduo se sentir mais motivado do que outro perante a mesma situação, deve-se à diferença de personalidades. Além desta variável, os indivíduos possuem um sistema de motivos básicos para cada situação como resultado da interacção ou interpretação de outras situações vivenciadas pelo indivíduo. Segundo Samulski e Noce, (002) em 1995, a motivação é caracterizada por um processo activo, intencional e dirigido a uma meta, o qual dependente da interacção de factores pessoais (intrínsecos) e ambientais (extrínsecos). De acordo com o modelo das determinantes da motivação, a motivação é formada por uma determinante energética (nível de activação) e uma determinante de direcção de comportamento (intenções, interesses, motivos e metas).

Na visão de Araújo et. al. (2007), a motivação é um estado interno regulado por necessidades que activam ou despertam o comportamento dirigido para a satisfação dessas necessidades; os motivos que foram estabelecidos pela experiência designam-se simplesmente por motivos, enquanto aqueles que emergem para satisfazer as necessidades básicas da sobrevivência foram denominados de impulsos.

O termo motivação, significa "acção de pôr em movimento" e parece ser originário das palavras latinas motu (movimento) e movere (mover), o que lhe confere uma ideia de movimento para ir de um local para outro. Deste modo, a motivação é entendida através de um conjunto de variáveis que estabelecem a razão que leva os indivíduos à escolha de um determinado desporto, assim como o seu empenho e permanência a longo prazo. Torna-se importante estudar a motivação, uma vez que existe necessidade em explicar e analisar os motivos que impulsionam os sujeitos a realizar acções, compreender o porquê da sua variação e duração ou não ao longo do tempo. A motivação é um conceito usado para perceber a complexidade do processo que organiza, direcciona e determina a intensidade do esforço do indivíduo. No estudo da motivação importa ter em conta duas dimensões no processo motivacional: a direcção e a intensidade. A direcção relaciona-se com a escolha da actividade a fim de alcançar certos objectivos, enquanto a intensidade diz respeito ao empenho do indivíduo numa qualquer actividade que vise a concretização de objectivos estabelecidos.

A motivação para a prática desportiva resulta da interacção entre factores pessoais e situacionais. Como factores pessoais podemos enumerar a personalidade, as necessidades, os interesses, os motivos, as metas e as expectativas; No que se refere aos factores situacionais temos o estilo de liderança, as facilidades, as tarefas atractivas, os desafios e as influências sociais. Mas quer uns como os outros também podem ser incentivos para a inércia.

No processo motivacional, pode-se subdividir a motivação de acordo com a fonte em 
intrínseca e extrínseca (Deci \& Ryan, 1985). Nesta perspectiva a motivação intrínseca como um conjunto de experiências de competência e interesse (prazer) que se devem sobrepor a reforços externos, como a obtenção de recompensas (motivação extrínseca).

Independente de factores externos motivadores, a motivação intrínseca pode-se tornar mais forte, verificando-se este facto em pessoas que se dedicam de forma intensa na prática de actividades (Cruz, 1996). Este autor realça que, este tipo de motivação está intimamente ligado a factores internos inerentes ao próprio sujeito, ou seja, os indivíduos foram intrinsecamente motivados para serem competentes, abertos à aquisição de novas competências e à procura de acção. Segundo este autor, os sujeitos procuram ainda, o prazer e a satisfação da realização de tarefas e a obtenção de benefícios que possibilitem o aumento progressivo das suas capacidades e níveis máximos de desempenho.

Por outro lado, a motivação extrínseca está dependente de vários factores de recompensa tais como: dinheiro, fama, sucesso, e reconhecimento. Estes factores interferem no indivíduo, sendo que a realização da tarefa deixa de ser o único objectivo pré-estabelecido (Moreno et. al., 2006). Assim, a motivação intrínseca e extrínseca possuem ambas grande influência na prática desportiva e na sua aderência, tendo grande impacto nos comportamentos e actuações dos atletas, influenciando-se mutuamente.

Tendo por base a teoria da auto-determinação de Deci e Ryan (1985), a motivação pode ser classificada considerando um continuum, com os seguintes níveis motivacionais: motivação intrínseca, motivação extrínseca auto-determinada, motivação extrínseca não autodeterminada e amotivação. Estes autores consideravam a dicotomia intrínseca - extrínseca elementar, daí o seu desenvolvimento teórico. Assim, com base na teoria destes autores, Kilpatrick, Hebert e Jacobsen (2002) num estudo que levaram acabo verificaram que os motivos para o comportamento foram: o divertimento, mestria e prazer para a amotivação intrínseca; os aspectos de saúde, o fitness e aspectos sociais foram os motivos correspondentes à motivação extrínseca auto-determinada; para a motivação extrínseca não auto-determinada foram apresentados como motivos: as recompensas, a pressão e o medo/ receio. Por último, no nível motivacional designado amotivação referem-se a incerteza e o abandono por parte do praticante. No entanto, esta também poderá surgir como referindo-se à falta de motivação que poderá resultar da percepção, por parte do indivíduo, da inexistência de relação entre as acções e os resultados do seu envolvimento levando a uma avaliação de que não existem motivos para continuar na actividade em questão. Deste modo, na amotivação, os comportamentos iniciam-se e regulam-se por "forças" sem controlo intencional do indivíduo, e dada a ausência de intenção não lhe podem ser atribuídas motivações intrínseca nem extrínsecas (Deci \& Ryan, 1985).

Um estudo realizado na Bélgica por Meuris em 1977 e descrito por Cruz (1996, pag. 306), que envolveu 1295 desportistas e 217 não desportistas com idades entre os 12 e 18 anos, de ambos os sexos, obteve os seguintes resultados: as razões de ordem pessoal como prazer no desporto, saúde, equilíbrio físico e intelectual, manutenção da forma e distracção eram consideradas mais importantes que as razões de ordem social (popularidade, encontrar pessoas) para a prática desportiva. No entanto, apenas $20.8 \%$ e $32.3 \%$ de raparigas e rapazes, respectivamente, afirmaram desejar triunfar ou ser campeões na actividade desportiva praticada.

Gil, Gross e Huddleston (1983) investigaram as razões para a participação desportiva numa amostra com 720 rapazes e 418 raparigas americanas, dos 8 aos 18 anos, que praticavam várias modalidades: basquetebol, luta, futebol, golfe, basebol, ténis, atletismo, ginástica e voleibol. O instrumento utilizado para avaliar as razões para a participação desportiva 
foi o "Questionário de Motivação para a Participação" que engloba 30 razões possíveis para a participação no desporto, sendo que o nosso estudo contou também com este questionário. Os dados revelaram os seguintes factores: "melhorar as competências", "divertimento", "aprender novas competências", "desafio" e "ser fisicamente saudável" foram as razões mais importantes para a prática desportiva. De entre as trinta, o "divertimento", "forma física", "saúde física", "melhoria de competências", "ambiente da equipa" e o "desafio" foram as principais razões apontadas para a prática desportiva. Estes autores num outro estudo qual participaram 365 jovens, com idades compreendidas entre os 8 e 19 anos, praticando natação de alta competição. Como factores menos importantes, assinalaram-se "agradar aos pais" ou aos "melhores amigos", "acalmar a tensão", "ser popular" e "viajar". Este estudo permitiu ainda, a identificação de 7 factores de motivação para a prática desportiva: "realização/estatuto", "ambiente da equipa”, "excitação/desafio", "forma/saúde física”, "descarga de energias", "desenvolvimento de competências" e "amizade". Notaram-se também diferenças ao nível do sexo: as nadadoras davam maior importância ao factor "amizade" e ao motivo "divertimento" quando comparadas com os elementos do sexo masculino.

Numa pesquisa efectuada por Buonomano, Cei e Mussino (1995), que estudou 2598 jovens atletas italianos com idades compreendidas entre os 9 e os 18 anos, envolvidos em várias modalidades desportivas, procurou-se identificar os motivos na participação desportiva. Os resultados indicaram que os principais motivos para a participação desportiva eram os seguintes (por ordem decrescente de importância): o "prazer e divertimento", motivos de or $\neg$ dem física (ex: "ser saudável e ficar mais forte"), razões de ordem social (ex: "estar com os amigos ou fazer novas amizades"), motivos competitivos (ex: "competir com os outros"), motivos relacionados com o desenvolvimento ou melhoria de competências e a ascensão social (ex: "ter estatuto social, ganhar dinheiro ou ser popular").

Cruz, Costa, Rodrigues e Ribeiro (1988) investigaram a motivação de 90 atletas e 19 ex-atletas de andebol, com idades compreendidas entre 15 e os 32 anos. De um modo geral, os atletas de andebol pareceram ser motivados para a prática, com o objectivo de desenvolverem as suas capacidades, manter e/ ou promover a saúde/forma física, pelo divertimento e descarga de energia proporcionada. Quanto aos ex-atletas, atribuíram também importância aos aspectos referidos anteriormente e ainda a motivos como a amizade, afiliação e a orientação para a equipa.

Serpa (1992) desenvolveu um estudo com 175 indivíduos com idades compreendidas entre os 10 e os 15 anos. Os motivos apontados como mais importantes foram: "estar em boa condição física", "trabalho em equipa", "aprender novas técnicas", "espírito de equipa" e "fazer exercício". Os menos importantes foram: "pretexto para sair de casa", "entrar em competição", "descarregar energias", "ultrapassar desafios" e "ter a sensação de ser importante". Um outro estudo, Vasconcelos-Raposo, Figueiredo e Granja (1996) os motivos mais importantes para a prática desportiva no sexo masculino foram: "estar em boa condição física", "aprender novas técnicas", "trabalhar em equipa", "atingir um nível desportivo elevado" e "manter a forma", enquanto para o sexo feminino, "estar com os amigos", "fazer novas amizades", "divertimento", "aprender novas técnicas" e "estar em boas condições físicas" foram apontadas como os motivos mais importantes.

Uma vez descritos aqueles que se apresentaram na literatura como os mais destacados, nesta temática, vai para mais de 30 anos, que os estudos, recorrendo a análise factoriais exploratórias apresentaram como constructos os seguintes: No caso do IMAAD foram: 1Aversão às práticas desportivas; 2- Estética; 
3- Falta de apoios /condições; 4- Desinteresse pelo esforço físico; e 5- Falta de tempo. No caso do QMAAD foram: 1- Realização / estatuto; 2- Objectivos desportivos; 3- Orientação para o grupo; 4- Excitação; 5- Divertimento; e 6- Influência Social (Pereira \& Vasconcelos-Raposo, 1997). Deste modo, o objectivo deste trabalho foi comparar por sexo, cumprimento ou não das recomendações para a prática desportiva, nível de actividade física e correlacionar os factores de ambos os questionários com os níveis de actividade física. Por último identificar os factores que se apresentam com maior e menor importância relativamente a cada um questionários utilizados.

\section{MÉTODO}

A presente investigação é um estudo transversal, os dados foram recolhidos num só momento. Apoia-se no paradigma quantitativo, assim como na perspectiva ética e modelo nomotético de investigação, visando a generalização e compreensão de padrões gerais de comportamento. $\mathrm{Na}$ medida em que foram efectuadas correlações paramétricas, podemos caracterizar este estudo como correlacional e ainda do tipo comparativo, dado que se analisaram diferenças entre alguns variáveis.

\section{Amostra}

A amostra deste estudo é constituída por 186 sujeitos, sendo que inicialmente foram aplicados 200 questionários, mas 14 questionários foram anulados pois verificou-se que não eram válidos por ausência de resposta ou por incompreensão da resposta assinalada. Definimos previamente um intervalo de idades que vai dos 18 aos 35 anos de idade (24.42 \pm 4.50$)$. Este estudo envolveu 86 elementos do sexo masculino (46.2\%) e 100 elementos do sexo feminino $(53.8 \%)$ residentes no interior norte de Portugal. Quanto ao estado civil, 78\% dos indivíduos são solteiros, $16.1 \%$ são casados, $1.6 \%$ são divorciados, $.5 \%$ são viúvos e $3.8 \%$ inserem-se na categoria "outros", englobando os sujeitos que não se encontram em nenhuma das situações referidas anteriormente.

No que diz respeito às habilitações literárias, o ensino secundário predomina com $56.5 \%$, sendo que $31.7 \%$ e $4.8 \%$ são licenciados e possuem o $3^{\circ}$ ciclo, respectivamente. A restante percentagem distribui-se na categoria de bacharelato $(2.7 \%)$, o $1^{\circ}$ e $2^{\circ}$ ciclo com a mesma proporção (1.6\%) e por último, $1.1 \%$ na categoria de mestrado.

Relativamente à profissão, $58.6 \%$ são estudantes, $27.4 \%$ englobam-se na categoria "outros", onde se encontram representadas as profissões para as quais não foi definida uma categoria específica tendo em conta que não apresentavam percentagem relevante na amostra recolhida. Quanto às restantes, 4.3\% são professores, $2.7 \%$ são desempregados, $2.2 \%$ barmen e as categorias de administrativo, funcionário público e fisioterapeuta apresentam a mesma percentagem de $1.6 \%$.

Quanto ao nível do envolvimento em prática de actividade física, a amostra caracteriza-se por ser "insuficientemente activa" (55\%), 25\% são moderadamente activos, $17 \%$ são inactivos e apenas $3 \%$ são muito activos. Tendo em conta que, é recomendado a prática de actividade física durante 30 minutos consecutivos ou fraccionados por dia (ACSM/ Pate et al., 1995), $96.8 \%$ da nossa amostra não atinge sendo que, apenas $3.2 \%$ atinge o nível recomendado de exercício físico.

Neste estudo foram utilizados o IMAAD (Inquérito de Motivações para a Ausência Actividade Desportiva) e o QMAD (Questionário de motivação para as actividades desportivas), com o objectivo de avaliar os motivos para a não prática e a prática desportiva, respectivamente.

\section{Instrumentos}

O IMAAD, desenvolvido por Pereira e Vasconcelos-Raposo (1997), é formado por 39 itens, precedido pela afirmação "As pessoas não praticam desporto porque ...”. É constituído por 5 factores: Factor 1 - Aversão despor- 
tiva/Insatisfação ( $\alpha$ de Cronbach $=.77$ ), factor 2 - Estética/Incompetência $(\alpha$ de Cronbach $=$ .72 ), factor 3 - Falta de apoio/Condições ( $\alpha$ de Cronbach $=.72$ ), factor $4-$ Desinteresse pelo esforço físico ( $\alpha$ de Cronbach $=.63$ ) e o factor 5 - Falta de tempo ( $\alpha$ de Cronbach $=.58)$. O factor 4 e 5 apresentam níveis de consistência interna abaixo do recomendado (.7), enquanto os restantes factores apresentam níveis satisfatórios. As respostas foram dadas numa escala do tipo Likert, sendo que o 1 representa "discordo plenamente", 2 "discordo", 3 "nem concordo nem discordo", 4 "concordo" e 5 "concordo plenamente".

O QMAD foi traduzido e adaptado do Participation Motivation Questionaire - PMQ (Gill e tal., 1983) traduzido e adaptado por Frias e Serpa (1991). Este instrumento é constituído por 6 factores, sendo o factor 1- Realização/Estatuto ( $\alpha$ de Cronbach $=$ .78), factor 2- Objectivos Desportivos ( $\alpha$ de Cronbach $=.55)$, factor 3- Orientação para o Grupo ( $\alpha$ de Cronbach $=.68$ ), factor 4 - Excitação ( $\alpha$ de Cronbach $=.59$ ), factor 5- Divertimento ( $\alpha$ de Cronbach $=.64$ ) e o factor 6 - Influência Social ( $\alpha$ de Cronbach $=.53$ ). Excepto o factor 1 que apresenta um valor de consistência interna satisfatória, os restantes factores do QMAD apresentam valores abaixo do valor de referência de .7.

Este instrumento é precedido pela seguinte expressão "As pessoas praticam actividades desportivas para...". As respostas foram dadas numa escala de tipo Likert, representando o 1- "nada importante", 2- "pouco importante", 3- "importante", 4- "muito importante"e o 5"totalmente importante".

Utilizou-se ainda, duas variáveis para avaliar a frequência de exercício físico numa semana normal e na última semana, definindo-se uma escala intervalar que varia entre 0 (inactivo) e 7 (muito activo). Para isso utilizamos a adaptação da escala de exercício físico de Prochaska, Sallis e Long (2001), pretendendo-se avaliar se os indivíduos são inactivos e activos na prática do exercício físico.

\section{Procedimentos}

No momento da distribuição dos questionários foi explicado a finalidade dos dados, isto é, perceber os motivos que levam à prática e não prática desportiva. Nessa altura todos assinaram o consentimento informado onde se explicitava a garantia do anonimato e se informava que poderiam desistir a qualquer momento e tal desistência em nada afectaria o sucesso do estudo. Durante o preenchimento nenhum dos participantes reportou qualquer dificuldade na interpretação das questões e todos finalizaram a tarefa. Os dados foram recolhidos sobre a forma de um questionário de auto-preenchimento.

Utilizamos o SPSS (Statistic Package for the Social Sciences), para construirmos a base de dados e elaborarmos o respectivo procedimento estatístico inicial. Procedeu-se à análise descritiva e de frequência, testes t para amostras independentes, análise de variância univariada (Anova), e correlações de Pearson.

\section{RESULTADOS}

Através da análise do quadro 1 , verifica-se que os valores de skewness (assimetria) encontram-se dentro do intervalo considerado para uma distribuição normal; quanto aos valores de kurtosis (achatamento da curva), existem 3 valores ligeiramente acima do intervalo, porém tendo em conta a dimensão da nossa amostra (reduzida), foram estudados como seguindo uma distribuição normal.

Na comparação de médias da variável sexo (quadro 2), observa-se que em geral não existem diferenças, excepto os factores "falta de tempo" $(p<.01)$ e "excitação" $(p=.01)$ nos quais as raparigas $(3.53 \pm .72$ e $3.86 \pm .70$, respectivamente) apresentam valores médios

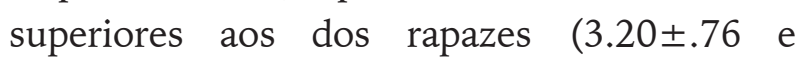
$3.56 \pm .75$, respectivamente).

No que diz respeito à comparação dos indivíduos que atingem e não atingem os níveis 
Quadro 1

Análise da média, desvio padrão, Skewness, Kurtosis e alpha de Cronbach

\begin{tabular}{cccccc} 
& Média & Desvio padrão & Skewness & Kurtosis & $\boldsymbol{\alpha}$ \\
\hline \multirow{2}{*}{ Aversão desportiva/insatisfação } & 2.55 & .54 & -.28 & .40 & .77 \\
Estética /incompetência & 2.85 & .61 & -.36 & 1.16 & .72 \\
Falta de apoios/condições & 2.52 & .57 & .53 & 1.03 & .72 \\
Desinteresse pelo esforço físico & 3.25 & .64 & -.76 & 1.36 & .63 \\
Falta de tempo & 3.38 & .76 & -.36 & -.22 & .58 \\
\hline Realização /estatuto & 2.18 & .75 & .74 & .38 & .78 \\
Objectivos desportivos & 3.61 & .58 & -.31 & 1.08 & .55 \\
Orientação para o grupo & 3.26 & .76 & .15 & -.12 & .68 \\
Excitação & 3.72 & .74 & -.34 & .54 & .59 \\
Divertimento & 3.23 & .63 & .27 & .25 & .64 \\
Influência social & 2.87 & .70 & .14 & -.08 & .53 \\
\hline
\end{tabular}

Quadro 2

Análise comparativa da variável por sexos

\begin{tabular}{ccccc}
\cline { 2 - 5 } & $\begin{array}{c}\text { Rapazes } \\
\text { M } \pm \text { DP }\end{array}$ & $\begin{array}{c}\text { Raparigas } \\
\text { M } \pm \text { DP }\end{array}$ & $t$ & $p$ \\
\hline Aversão desportiva/insatisfação & $2.50 \pm .56$ & $2.59 \pm .51$ & 1.17 & .24 \\
Estética/incompetência & $2.78 \pm .70$ & $2.91 \pm .52$ & 1.33 & .19 \\
Falta de apoios/condições & $2.50 \pm .61$ & $2.53 \pm .53$ & .26 & .79 \\
Desinteresse pelo esforço físico & $3.20 \pm .64$ & $3.28 \pm .65$ & .86 & .39 \\
Falta de tempo & $3.20 \pm .76$ & $3.53 \pm .72$ & 3.08 & .001 \\
\hline Realização /estatuto & $2.28 \pm .77$ & $2.09 \pm .73$ & -1.69 & .09 \\
Objectivos desportivos & $3.62 \pm .68$ & $3.60 \pm .49$ & -.16 & .87 \\
Orientação para o grupo & $3.23 \pm .88$ & $3.28 \pm .64$ & .46 & .64 \\
Excitação & $3.56 \pm .75$ & $3.86 \pm .70$ & 2.78 & .01 \\
Divertimento & $3.30 \pm .67$ & $3.18 \pm .59$ & -1.39 & .17 \\
Influência social & $2.88 \pm .71$ & $2.86 \pm .69$ & -.23 & .82 \\
\hline
\end{tabular}

recomendados de actividade física (quadro 3), para o factor "influência social" $(p<.05)$ o grupo que atinge (3.28 \pm .33$)$ apresenta valores médios superiores aos que não atingem (2.85 \pm .70$)$, quanto aos restantes valores não apresentam diferenças significativas.

Da análise comparativa das categorias da prática de exercício físico (quadro 4), constatou-se que o factor "influência social" é o único que apresenta valores significativos $(p$ $<.05)$; os valores médios vão aumentando à medida que se passa para uma categoria em que o sujeito é mais activo no que diz respeito

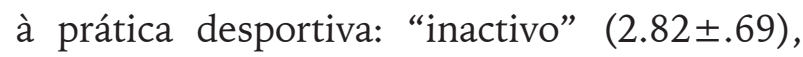
"insuficientemente activo" (2.76 .67$)$, "moderadamente activo" (3.09 \pm .74$)$ e "muito activo" (3.28 \pm .33$)$.

A análise correlacional entre os factores do IMAAD e do QMAD com a frequência de exercício físico (quadro 5), mostrou que o factor "falta de tempo" correlaciona-se negativa e significativamente $(r=-.17 ; p<.05)$; verifica-se também uma correlação positiva e altamente significativa ao nível estatístico para o factor "influência social" $(r=.21 ; p<.01)$.

Os motivos apontados como mais importantes para a não prática desportiva, foram semelhantes distinguindo-se apenas para rapazes "falta de interesse, de vontade" e para as raparigas o motivo "falta de tempo" (quadro 6). 
Quadro 3

Análise comparativa dos sujeitos que não atingem e atingem os níveis recomendados de actividade física

\begin{tabular}{|c|c|c|c|c|c|}
\hline & & $\begin{array}{c}\text { Não atinge } \\
M \pm D P\end{array}$ & $\begin{array}{l}\text { Atinge } \\
M \pm D P\end{array}$ & $t$ & $p$ \\
\hline \multirow{5}{*}{$\sum_{i}$} & Aversão desportiva/insatisfação & $2.54 \pm .54$ & $2.61 \pm .20$ & -.28 & .78 \\
\hline & Estética /incompetência & $2.84 \pm .62$ & $3.04 \pm .44$ & -.79 & .43 \\
\hline & Falta de apoios/condições & $2.52 \pm .57$ & $2.42 \pm .42$ & .44 & .66 \\
\hline & Desinteresse pelo esforço físico & $3.24 \pm .65$ & $3.30 \pm .33$ & -.21 & .84 \\
\hline & Falta de tempo & $3.39 \pm .76$ & $2.89 \pm .66$ & 1.62 & .11 \\
\hline \multirow{6}{*}{ 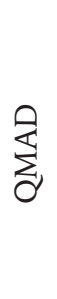 } & Realização /estatuto & $2.17 \pm .76$ & $2.41 \pm .56$ & -.80 & .43 \\
\hline & Objectivos desportivos & $3.61 \pm .59$ & $3.71 \pm .53$ & -.41 & .68 \\
\hline & Orientação para o grupo & $3.25 \pm .77$ & $3.50 \pm .45$ & -.80 & .43 \\
\hline & Excitação & $3.72 \pm .75$ & $3.92 \pm .38$ & -.65 & .52 \\
\hline & Divertimento & $3.23 \pm .63$ & $3.46 \pm .49$ & -.89 & .37 \\
\hline & Influência social & $2.85 \pm .70$ & $3.28 \pm .33$ & -2.95 & .02 \\
\hline
\end{tabular}

Quadro 4

Análise dos valores médios (ANOVA) das categorias da frequência de prática desportiva

\begin{tabular}{|c|c|c|c|c|c|c|c|}
\hline & & & & & & & \\
\hline & & $\begin{array}{c}\text { Inactivo } \\
\mathrm{M} \pm \mathrm{DP}\end{array}$ & $\begin{array}{c}\text { Insufic activo } \\
\mathrm{M} \pm \mathrm{DP}\end{array}$ & $\begin{array}{c}\text { Moderado activo } \\
\mathrm{M} \pm \mathrm{DP}\end{array}$ & $\begin{array}{c}\text { Muito activo } \\
\qquad \pm \pm D P\end{array}$ & $\boldsymbol{F}$ & $p$ \\
\hline \multirow{5}{*}{ 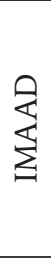 } & Aversão desportiva/insatisfação & $2.48 \pm .54$ & $2.55 \pm .55$ & $2.67 \pm .52$ & $2.61 \pm .20$ & 1.18 & .32 \\
\hline & Estética/incompetência & $2.84 \pm .50$ & $2.80 \pm .58$ & $2.93 \pm .76$ & $3.04 \pm .44$ & .73 & .54 \\
\hline & Falta de apoios/condições & $2.63 \pm .61$ & $2.51 \pm .49$ & $2.47 \pm .70$ & $2.42 \pm .42$ & .57 & .64 \\
\hline & Desinteresse pelo esforço físico & $3.20 \pm .54$ & $3.19 \pm .67$ & $3.38 \pm .68$ & $3.23 \pm .33$ & .97 & .41 \\
\hline & Falta de tempo & $3.38 \pm .79$ & $3.47 \pm .71$ & $3.24 \pm .83$ & $2.89 \pm .66$ & 1.89 & .13 \\
\hline \multirow{6}{*}{$\sum_{d}$} & Realização/estatuto & $2.31 \pm .59$ & $2.10 \pm .70$ & $2.22 \pm .96$ & $2.42 \pm .56$ & .98 & .40 \\
\hline & Objectivos desportivos & $3.53 \pm .60$ & $3.57 \pm .57$ & $3.74 \pm .59$ & $3.71 \pm .53$ & 1.14 & .34 \\
\hline & Orientação para o grupo & $3.16 \pm .75$ & $3.25 \pm .71$ & $3.29 \pm .92$ & $3.50 \pm .45$ & .42 & .74 \\
\hline & Excitação & $3.76 \pm .81$ & $3.79 \pm .72$ & $3.62 \pm .76$ & $3.92 \pm .38$ & 1.03 & .38 \\
\hline & Divertimento & $3.24 \pm .60$ & $3.17 \pm .46$ & $3.32 \pm .67$ & $3.46 \pm .49$ & .91 & .44 \\
\hline & Influência social & $2.82 \pm .69$ & $2.76 \pm .67$ & $3.09 \pm .74$ & $3.28 \pm .33$ & 3.22 & .02 \\
\hline
\end{tabular}

Quadro 5

Análise correlacional da frequência de exercício físico com os factores do IMAAD e QMAD

\begin{tabular}{cccc} 
& $r$ & $p$ \\
\hline & Aversão desportiva/insatisfação & .13 & .08 \\
Estética/incompetência & .08 & .29 \\
Falta de apoios/condições & -.10 & .19 \\
& Desinteresse pelo esforço físico & .12 & .10 \\
& Falta de tempo & $-.17^{*}$ & .02 \\
\hline & Realização/estatuto & .01 & .92 \\
Objectivos desportivos & .13 & .08 \\
\multirow{2}{*}{$\begin{array}{l}\text { Orientação para o grupo } \\
\text { Excitação }\end{array}$} & .09 & .23 \\
& Divertimento & -.01 & .88 \\
& Influência social & .09 & .24 \\
\hline
\end{tabular}

Nota: ${ }^{*} p<.05,{ }^{* *} p<.01$ 
Quanto aos motivos mais importantes para a prática desportiva (quadro 7), os rapazes apontam o motivo "divertimento" e as raparigas o motivo "manter a forma", sendo que os restantes factores foram idênticos em ambos os grupos.

No que se refere aos motivos menos importantes para a prática desportiva (quadro 8), apenas um motivo é distinto para os grupos: nos rapazes o motivo "pretexto para sair de casa" e nas raparigas o motivo "receber prémios".

Do estudo da amostra, verificou-se que os motivos mais importantes para a prática desportiva foram "estar em boa condição física", "fazer exercício"e "manter a forma", em contrapartida para a não prática foram referidos os motivos "falta de hábitos desportivos", "por preguiça" e "falta de interesse, de vontade" (quadro 9).

Os motivos "ser conhecido", "ter a sensação de ser importante" e "pretexto para sair de casa", foram sugeridos como os menos importantes para a prática, enquanto, para a não prática foram referidos os motivos "desporto não traz benefícios", "não querem mudar o seu visual" e "o desporto é aborrecido, maçador e chato" (quadro 10).

Quadro 6

Motivos mais importantes para a não prática desportiva entre sexos

\begin{tabular}{cccc}
\hline & Rapazes & \multicolumn{2}{c}{ Raparigas } \\
& $\boldsymbol{M}$ & Falta de hábitos desportivos & 3.95 \\
\hline Falta de hábitos desportivos & 3.86 & Por preguiça & 3.92 \\
Por preguiça & 3.78 & Falta de tempo & 3.74 \\
\hline
\end{tabular}

Quadro 7

Motivos mais importantes para a prática desportiva entre sexos

\begin{tabular}{cccc}
\hline & Rapazes & \multicolumn{2}{c}{ Raparigas } \\
& $\boldsymbol{M}$ & Estar em boa condição física & 4.14 \\
\hline Estar em boa condição física & 4.03 & Manter a forma & 4.09 \\
Divertimento & 4.00 & Fazer exercício & 3.99 \\
Fazer exercício & 4.00 & & \\
\hline
\end{tabular}

Quadro 8

Motivos menos importantes para a prática desportiva entre sexos

\begin{tabular}{cccc}
\hline & Rapazes & & \multicolumn{2}{c}{ Raparigas } \\
& $\boldsymbol{M}$ & Ser conhecida & 1.85 \\
Ser conhecido & 2.13 & Ter a sensação de ser importante & 2.08 \\
Pretexto para sair de casa & 2.29 & Receber prémios & 2.20 \\
\hline Ter a sensação de ser importante & 2.31 & & \\
\hline
\end{tabular}

Quadro 9

Motivos mais importantes para a prática e não prática na amostra

\begin{tabular}{cccc}
\hline & QMAD & & IMAAD \\
& $\boldsymbol{M}$ & Falta de hábitos desportivos & 3.91 \\
\hline Estar em boa condição física & 4.09 & Por preguiça & 3.85 \\
Fazer exercício & 3.99 & Falta de interesse/ de vontade & 3.61 \\
Manter a forma & 3.98 & \\
\hline
\end{tabular}


Quadro 10

Motivos menos importantes para a prática e não prática na amostra

\begin{tabular}{cccc}
\hline & QMAD & & IMAAD \\
& $M$ & & $M$ \\
\hline Ser conhecido & 1.98 & O desporto não traz benefícios & 1.42 \\
Ter a sensação de ser importante & 2.19 & Não querem mudar o seu "visual" & 1.76 \\
Pretexto para sair de casa & 2.27 & O desporto é "aborrecido", "maçador" e "chato" & 2.11 \\
\hline
\end{tabular}

\section{DISCUSSÃO}

Dos 5 objectivos definidos para o presente estudo, foi possível constar diferenças entre os sexos numa das dimensões do IMAAD: falta de tempo, onde as mulheres pontuaram mais alto que os homens. Nas comparações por satisfação das recomendações para a actividade física e nível de envolvimento encontraram-se diferenças na variável influência social em que na primeira as mulheres obtiveram um score mais elevado, mas na segunda foram os homens. As correlações não apresentaram quaisquer efeitos estatísticos.

O factor falta de tempo apresentou valores médios significativos mais elevados para as raparigas do que para os rapazes, ou seja, verificou-se que as raparigas pensam que as pessoas não praticam actividades desportivas por falta de tempo. Igualmente, para o factor excitação, as raparigas referem este factor para a prática desportiva com valores médios superiores aos rapazes.

Aquando da comparação dos grupos que atingem e não atingem os níveis recomendados de actividade física, o facto do grupo que atinge apresentar valores médios superiores no factor influência social leva-nos a pensar que as pessoas que mais praticam actividades desportivas atribuem mais importância à influência social. De algum modo este resultado é coerente com aquilo que é actualmente percepcionado no que se refere aos requisitos para se obter corpos esbeltos.

Este factor também apresenta valores significativos na comparação das categorias da frequência de prática desportiva, verificando-se uma diminuição dos valores médios dos inactivos para os insuficientemente activos sendo que para as categorias moderadamente activo e muito activo se verificou um aumento dos valores médios, ou seja, mais uma vez este factor foi referido mais frequentemente por sujeitos que mais aderem à prática desportiva. Tal facto pode expressar simultaneamente uma maior consciência do que é necessário fazer para manter níveis adequados de saúde assim como também maior cedência às pressões sociais.

Apesar de não apresentar valores estatisticamente significativos, pela análise das médias pode-se constatar que o factor "falta de tempo" apresentou um aumento da categoria dos inactivos para os insuficientemente activos, porém as médias diminuem nas seguintes categorias onde a prática é mais frequente. Assim, quanto mais activo é o sujeito tende a diminuir a referência do factor tempo para a não prática desportiva, pois por vezes não se trata de falta de tempo mas de uma má gestão do tempo. Frequentemente as pessoas dão como desculpa a falta de tempo para não aderirem à prática de exercício físico. Os resultados do nosso estudo tendem a confirmar a ideia que esse é um falso argumento.

$\mathrm{Na}$ análise correlacional, o factor falta de tempo e a frequência de prática desportiva correlacionam-se negativamente apresentando valores significativos; este dado permite-nos afirmar que existe uma relação entre estas duas variáveis, isto é, à medida que os indivíduos praticam a falta de tempo é menos referenciada e aqueles que menos praticam, a faltam de tempo é um factor muito anotado; deste modo, as variáveis variam 
inversamente. O factor influência social correlaciona-se positivamente com a frequência de prática desportiva, concluindo-se que este factor se torna muito importante quando a frequência de prática desportiva aumenta. Os dados sugerem que o factor influência social se constitui como um factor muito importante para indivíduos que adoptam um estilo de vida activo, sendo que este factor se integra na motivação extrínseca auto-determinada.

No que diz respeito aos motivos mais importantes para a não prática desportiva, verificou-se que ambos os grupos da variável sexo referiam a "falta de hábitos desportivos" e "por preguiça" como os mais importantes; sendo que para os rapazes, o motivo "falta de interesse, de vontade", e para as raparigas o motivo "falta de tempo" foram também referidos como mais importantes. Os motivos "estar em boa condição física" e "fazer exercício" foram assinalados por rapazes e raparigas como os mais importantes para a prática desportiva; para as raparigas, o motivo "manter a forma" é também referido como mais importante e o "divertimento" nos rapazes. O motivo "pretexto para sair de casa" para os rapazes e o motivo "receber prémios" (motivação extrínseca não auto-determinada) para as raparigas, foram mencionados como um dos menos importantes para a prática desportiva; porém, ambos os grupos apontam os motivos "ser conhecido" e "ter a sensação de ser importante" como menos importantes na prática desportiva. Tratam-se, portanto, maioritariamente, de motivos pertencentes ao nível motivacional extrínseco autodeterminado, segundo Deci and Ryan (1985).

Deste modo, apesar de haver bastantes semelhanças entre os grupos acerca dos factores mais e menos importantes para a prática e mais importantes para a não prática desportiva, existem pequenas diferenças entre os grupos. A existência de diferenças entre grupos foi já apontada por Vasconcelos-Raposo et al. (1996) e Figueiredo (1997), porém os motivos apresentados por cada um dos grupos não vão ao encontro com os do nosso estudo.

Os motivos mais importantes apontados pela totalidade da amostra foram: "estar em boa condição física", "fazer exercício" e "manter a forma"; estes dados vêm confirmar os estudos de Meuris (1977, cit. Cruz,1996), Gould, Feltz, Weiss e Petlichkoff (1982), Cruz, Costa, Rodrigues e Ribeiro (1988) e Serpa (1992), nos quais também foram sugeridos estes motivos como os mais importantes, para além de outros. Trata-se também de motivação extrínseca autodeterminada, segundo a teoria apresentada anteriormente.

No que concerne aos motivos menos importantes para a prática, os participantes deste estudo consideram que "ser conhecido", "ter a sensação de ser importante" e " pretexto para sair de casa" os menos relevantes. Estes dois últimos motivos foram também apresentados no estudo de Serpa (1992), juntamente com outros e foram também motivos relacionados com a motivação extrínseca auto-determinada.

Este estudo permitiu verificar que, a “ falta de hábitos desportivos", "por preguiça" e "falta de interesse, de vontade" foram os motivos fundamentais para a não prática desportiva. Por outro lado, "o desporto não traz benefícios", "não querem mudar o seu visual", "o desporto é aborrecido maçador e chato" foram os motivos considerados menos importantes para a não prática.

O facto de a nossa amostra ser maioritariamente constituída por jovens estudantes e com uma faixa etária compreendida entre os 18 e os 35 anos torna-se limitativo pois os estudos identificados na revisão da literatura abrangiam maioritariamente adolescentes. Além disso, o facto dos grupos submetidos a comparação não serem homogéneos torna-se também limitativo porque pode levar a conclusões desacertadas; convém referir ainda que, outra limitação deste estudo prende-se no facto do instrumento QMAD não estar 
validado. Em futuras investigações, sugere-se a utilização e uma amostra de maiores dimensões, a utilização de uma faixa etária mais abrangente e também dar mais relevância às motivações para a não prática desportiva.

\section{CONCLUSÃO}

Apesar de se passarem os anos, os resultados sugere que há aspectos de ordem sociocultural que prevalecem e que se fazem sentir na resistência à mudança. Por outras palavras, quaisquer que tenham sido as políticas que visaram promover a prática desportiva no país essas não produziram qualquer efeito.

Agradecimentos:

Nada declarado.

\section{Conflito de Interesses:}

Nada declarado.

\section{Financiamento:}

Nada declarado.

\section{REFERENCES}

Araújo, A., Pimenta, F., Banaúna, M., Junior, J., Silva, A., \&, ... Paula, A. (2007). Factores motivacionais que levam as pessoas a procurarem por academias para a prática de exercício físico. EFDeportes, 12 (115). Acedido em 09/05/2008 a partir de http:// www.efdeportes.com/efd115/fatoresmotivacionais-que-levam-as-pessoas-aprocurarem-por-academias.htm

Buonamano, R; Cei, A. \& Mussino, A. (1995). Participation motivation in Italian youth sport. The Sport Psychologist, 9, 265-281.

Cruz, J., Costa, F., Rodrigues, R., \& Ribeiro, F. (1988). Motivação para a prática e competição desportiva. Revista Portuguesa de Educação, 1, 113-124.

Cruz, J.F. (1996). Motivação para a competição e prática desportiva. In Manual de Psicologia do Desporto, (pp. 305-331).
Braga: S.H.O- Sistemas Humanas e Organizacionais, Lda.

Deci, E.L. \& Ryan, R.M. (1985). Intrinsic motivation and self-determination in human behavior. New York: Plenum.

Figueiredo, A. (1997). Factores de Motivação para a prática desportiva: Estudo de caracterização da população de alunos da Licenciatura $e$ Educação Física e Deporto da UTAD. Vila Real. Universidade de Trás-os-Montes e Alto Douro.

Frias, J., \& Serpa, S. (1991). Factores de motivação para a actividade gímnica no quadro da ginástica geral, ginástica de manutenção e ginástica de representação. In J. Bento, \& A. Marques (Eds.). As Ciências do Desporto e a Prática Desportiva, 1, 169-179.

Gill, D., Gross, J., \& Huddleston, S. (1995). Participation motivation in youth sports. International Journal of Sport Psychology, 14, 1-14.

Gould, D., Feltz, D., Weiss, M., \& Petlichkoff, L. (1982). Participation motives in competitive swimmers. In T. Orlick, J. Partington, \& J. Salmela (Eds), Mental training for coaches and athletes. Otawa: Coaching Association of Canada.

Kilpatrick, M., Hebert, E., \& Jacobsen, D. (2002). Physical activity motivation: A practitioner's guide to self-determination theory. Journal of Physical Education, Recreation, and Dance, 73(4), 36-41. http:// dx.doi.org/10.1080/07303084.2002.1060 7789

Moreno, R; Dezan, F.; Duarte, L. \& Schwartz, G. (2006). Persuasão e motivação: Interveniências na actividade física e no esporte. Revista digital, 11 (103). Acedido em 03/05/2008 a partir de http://www. efdeportes.com/efd103/motivacao.htm

Pereira, P., \& Vasconcelos-Raposo, J. (1997). As motivações e a prática desportiva. Análise descritiva, factorial e comparativa dos factores motivacionais 
para a participação ou não em actividade desportivas em jovens de Baião. In A. Fonseca (Ed.), Estudos sobre Motivação (pp. 78- ) Porto: FCDEF.

Prochaska, J., Sallis, J., \& Long, B. (2001). A physical activity screening measure for use with adolescents in primary care. Archives of Pediatric Adolescence Medicine, 155, 554-599.

Samulski, D \& Noce, F. (2002). Perfil psicológico de atletas paraolímpicos brasileiros. Revista digital, 8 (4). Acedido em 02/05/2008 a partir http://www. efdeportes.com/efd55/motiv1.htm
Serpa, S. (1992). Motivação para a prática desportiva: Validação preliminar do questionário de motivação para a prática desportiva (pp. 89-97). In F. Sobral \& A. Marques (eds), FACDEX. Ministério da Educação: Lisboa. Direcção Geral dos Desportos

Vasconcelos-Raposo, J., Figueiredo, A., Granja, P. (1996) Factores de motivação dos jovens para a prática desportiva. Vila Real. Universidade de Trás-os-Montes e Alto Douro.

Weinberg, R. \& Gould, D. (1995). Foundations of Sport and Exercise Psychology. Champaign, IL: Human Kinetics. 